\title{
ADVENTITIOUS SHOOT REGENERATION FROM LEAF AND STEM EXPLANTS OF SALIX MATSUDANA KOIDZ
}

\author{
Liu Xiaoxia, Sui Jinkai ${ }^{1}$, Zhang Jianguo, Luo Ying and Rao Guodong* \\ State Key Laboratory of Tree Genetics and Breeding, Research Institute of Forestry, \\ Chinese Academy of Forestry, Beijing 100091, China
}

Keywords: Adventitious shoot, Regeneration, Micropropagation, Salix matsudana

\begin{abstract}
Currently, the leaf and stem as explants for rapid propagation in vitro remained unknown in Salix matsudana. Multiple shoots were regenerated from leaf and stem (stem apex and stem with axil). The optimum medium for callus regeneration and shoots induction from leaf was on WPM medium containing $6.0 \mathrm{mg} / \mathrm{l}$ zeatin $(\mathrm{Z})$ and $0.75 \mathrm{mg} / \mathrm{l} \mathrm{NAA}$. The optimum medium of shoot induction from stem apex was on MS medium supplemented with $8.0 \mathrm{mg} / \mathrm{l} \mathrm{Z}$ and $1.0 \mathrm{mg} / \mathrm{l} \mathrm{NAA}$, and from stem with axil was on MS with $8.0 \mathrm{mg} / \mathrm{l}$ $\mathrm{Z}$ and $0.5 \mathrm{mg} / \mathrm{l} \mathrm{NAA}$. Rooting of regenerated shoots was obtained on the same medium supplemented with $1.0 \mathrm{mg} / \mathrm{l}$ activated charcoal.
\end{abstract}

The genus Salix L. which includes, approximately 300 - 500 species, is widely distributed in temperate and cold regions in the Northern Hemisphere (Argus 1997). Limitations in the use of Salix species for renewable energy and phytoremediation include their inability to resist pests and diseases, the requirements for additional fertilizers and water, the inadequacy for the metabolism, the slow time-scale for remediation, and the fact that heavy metal accumulation is limited primarily to roots, which complicates the collection and elimination of toxins (Dowling and Doty 2009, Karp et al. 2011). To overcome these limitations, a high-frequency micropropagation system is needed to produce enormous number of virus-free plantlets of these species, which could save field space and time in conventional breeding.

Micropropagation from axillary or adventitious buds is a useful technique for regeneration system construction. Previously, some researchers have reported axillary buds' multiplication in Salix species (Neuner and Beiderbeck 1993, Agrawal and Gebhardt 1994). However, there are only a few published reports on the micropropagation of Salix plants from adventitious buds or somatic embryos (Lyyra et al. 2006, Yang et al. 2013). Yang et al. (2013) reported that multiple shoots were induced directly from embryonic shoot apices of germinating seeds of $S$. matsudana, and the highest induction frequency was obtained on the medium containing $4.5 \mu \mathrm{M}$ zeatin $(\mathrm{Z})$ and $0.54 \mu \mathrm{M}$ NAA. Although they obtained the transgenic plants, the hereditary basis of these regenerated plants was obviously inconformity due to the gametogamy of the seeds. Since reports on micropropagation of $S$. matsudana is not available by taking leaf and stem, the objective of the present study was to set up a regeneration system for the willow using leaf and stem as explants.

BAP, Z and TDZ combined with NAA and IAA were used for callus and shoot regeneration. One-year old shoots were collected from mature willow and young leaves were excised from the annual shoots and surface sterilized (70\% ethanol for different durations within 30,60 or $90 \mathrm{sec}$, dipped in $1 \%$ sodium hypochlorite for 5,6 or $7 \mathrm{~min}$, followed by rinses with sterile water for 3

*Author for correspondence: <rgd@caf.ac.cn>. ${ }^{1}$ College of Agronomy and Biotechnology, Hebei Normal University of Science and Technology, Qinhuangdao 066000, China. 
min). Following surface sterilization, two ends of the nodal segments and edges of the leaf explants were cut off for new wounds to enhance the absorption of nutrients and increase the induction frequency. Then, they were inoculated in the culture medium with different plant growth regulators. Three frequently used cytokinins including BAP, Z and TDZ and two media (MS and WPM) were tested to induce the formation of callus. The optimal adventitious buds were then obtained by adding various combinations of two main auxin (NAA and IAA) with different concentrations on the optimal callus induction medium supplemented with $30 \mathrm{~g} / \mathrm{l}$ sucrose, followed by addition of $6.5 \mathrm{~g} / \mathrm{l}$ agar. Fifty explants in five vessels were analyzed to optimize the parameters of induction rate. Each experiment was repeated at least three times. The explants were incubated in a plant tissue culture room at $25^{\circ} \mathrm{C}$ with a $14 \mathrm{hrs}$ photoperiod and a light intensity of 3000 lux. Media were replaced monthly, and the emergence and type of callus and any adventitious bud formation were recorded weekly. After the adventitious shoots reached a length more than $2 \mathrm{~cm}$, they were excised and transferred to rooting media containing the same PGRs and supplemented with $1.0 \mathrm{mg} / \mathrm{l}$ activated charcoal (AC). The data of callus and shoots induction with different plant growth regulators (PGRs) concentration and combination as well as culture media were analyzed using origin 8.6. One-way ANOVA was performed using statistical package for the social sciences (SPSS) software (SPSS Inc., Chicago, IL, USA).

Callus from leaf explants formed at the edges of leaf discs in MS and WPM with BAP, Z and TDZ. The induction rates on MS medium with different concentrations of BAP, zeatin and TDZ are presented in Table 1. With the increase of TDZ concentration, callus regeneration in the explants dramatically declined to nearly zero. On WPM medium, the similar result was observed for callus induction (Table 1). The present results showed that concentration of $1.0 \mathrm{mg} / \mathrm{l} \mathrm{BAP}$ was optimal for the calli induction.

The cytokinin-auxin combination has been used widely for shoot regeneration in varieties of protocols performed for other species, such as Trifolium alexandrinum L. (Abogadallah and Quick 2010), Populus euphratica (Zhou et al. 2012), Malus zumi (Xu et al. 2008), Paulownia tomentosa (Corredoira et al. 2008) and so on. In endangered multipurpose medicinal plant Coleus forskohlii, the optimal direct shoots regeneration (76.4\%) was obtained in MS medium with $5.0 \mathrm{mg} / \mathrm{l} \mathrm{BAP}$ after 28 days incubation (Krishna et al. 2010). The present results showed that $1.0 \mathrm{mg} / \mathrm{l}$ of BAP was optimal for the calli and shoots induction. NAA and IAA were tested in combination with the BAP and Z, separately. The optimal combination was $6.0 \mathrm{mg} / \mathrm{l} \mathrm{Z}$ with $0.75 \mathrm{mg} / \mathrm{l} \mathrm{NAA}$ on WPM medium, and it was better than using BAP alone, which is similar to the studies of Saussurea involucrate (Guo et al. 2007). On MS medium supplemented with BAP and NAA, the leaf discs of willow swelled and showed callus on the wounded edges and differentiated into adventitious buds after further four weeks. The highest callus induction frequency was $95.3 \%$, and the optimal adventitious bud's induction rates was $25.0 \%$, which were incubated on the medium with $0.5 \mathrm{mg} / \mathrm{l}$ NAA (Fig. 1A). As a natural cytokinin, $Z$ was also combined with NAA for callus and shoot inducing from willow leaf discs and shoot tips. Callus induction rate ranged from 76.5 to $89.3 \%$ (Fig. 1A) and the highest shoot induction rate was $31.6 \%$ with $0.5 \mathrm{mg} / \mathrm{l} \mathrm{NAA}$ (Fig. 1C). The same concentration of BAP and NAA, Z and NAA were used on the WPM medium, and the optimal shoot induction was 16.2 and $40.2 \%$, separately (Fig. 1C). In MS medium containing IAA with BAP, the highest callus and shoots production frequency was at 76.2 and $10.7 \%$, respectively which was induced on the optimal medium supplemented with $0.5 \mathrm{mg} / \mathrm{l} \mathrm{IAA}$. Z ( $8.0 \mathrm{mg} / \mathrm{l})$ also combined with IAA on MS medium, and the highest callus and shoots production frequency was 78.0 and $11.3 \%$, respectively. The same concentrations of BAP and IAA, Z and IAA were used on the WPM medium, and the optimal shoot induction was 8.8 and $14.7 \%$, separately (Fig. 1B, D). 
Table 1. Effect of BAP, $Z$ and TDZ on callus induction frequency from leaf explants of S. matsudana on MS and WPM media.

\begin{tabular}{|c|c|c|c|c|}
\hline \multirow{2}{*}{ Medium } & \multicolumn{2}{|c|}{ Growth regulator $(\mathrm{mg} / \mathrm{l})$} & \multicolumn{2}{|c|}{ Rate of callus induction (\%) } \\
\hline & BAP & $\mathrm{Z}$ & TDZ & \\
\hline MS & 0.25 & & & $29.0 \pm 1.15 \mathrm{f}$ \\
\hline$"$ & 0.5 & & & $73.5 \pm 2.17 \mathrm{c}$ \\
\hline$"$ & 1 & & & $84.0 \pm 2.32 b$ \\
\hline$"$ & 2 & & & $64.4 \pm 2.45 \mathrm{~d}$ \\
\hline$"$ & 4 & & & $52.1 \pm 4.57 \mathrm{e}$ \\
\hline$"$ & & 1 & & $62.0 \pm 3.80 \mathrm{~d}$ \\
\hline$"$ & & 2 & & $74.7 \pm 2.36 \mathrm{c}$ \\
\hline$"$ & & 4 & & $74.9 \pm 6.96 c$ \\
\hline$"$ & & 6 & & $78.1 \pm 5.13 \mathrm{c}$ \\
\hline$"$ & & 8 & & $98.0 \pm 0.02 \mathrm{a}$ \\
\hline$"$ & & & 0.1 & $11.4 \pm 1.07 \mathrm{~g}$ \\
\hline$"$ & & & 0.25 & $27.0 \pm 1.81 \mathrm{c}$ \\
\hline " & & & 0.5 & 0 \\
\hline$"$ & & & 1 & 0 \\
\hline$"$ & & & 2 & 0 \\
\hline WPM & 0.25 & & & $95.4 \pm 2.28 \mathrm{a}$ \\
\hline$"$ & 0.5 & & & $94.7 \pm 1.12 \mathrm{a}$ \\
\hline$"$ & 1 & & & $97.3 \pm 3.06 \mathrm{a}$ \\
\hline$"$ & 2 & & & $76.3 \pm 4.16 \mathrm{~b}$ \\
\hline$"$ & 4 & & & $63.3 \pm 4.47 \mathrm{~d}$ \\
\hline$"$ & & 1 & & $64.7 \pm 1.20 \mathrm{~d}$ \\
\hline$"$ & & 2 & & $71.4 \pm 5.30 \mathrm{c}$ \\
\hline$"$ & & 4 & & $71.4 \pm 3.13 \mathrm{c}$ \\
\hline$"$ & & 6 & & $98.0 \pm 2.04 \mathrm{a}$ \\
\hline$"$ & & 8 & & $94.8 \pm 3.15 \mathrm{a}$ \\
\hline$"$ & & & 0.1 & $52.3 \pm 0.96 \mathrm{e}$ \\
\hline$"$ & & & 0.25 & $50.2 \pm 2.70 \mathrm{e}$ \\
\hline$"$ & & & 0.5 & $17.5 \pm 0.73 f$ \\
\hline$"$ & & & 1 & 0 \\
\hline$"$ & & & 2 & 0 \\
\hline
\end{tabular}

Rate of callus induction was defined as the percentage of explants with white and spongy callus in total explants. About 50 explants were cultured for each treatment and the data were calculated from at least three independent experiments. Numbers with different letters indicate significant differences by the DMRT $(\mathrm{p} \leq$ $0.05)$. 


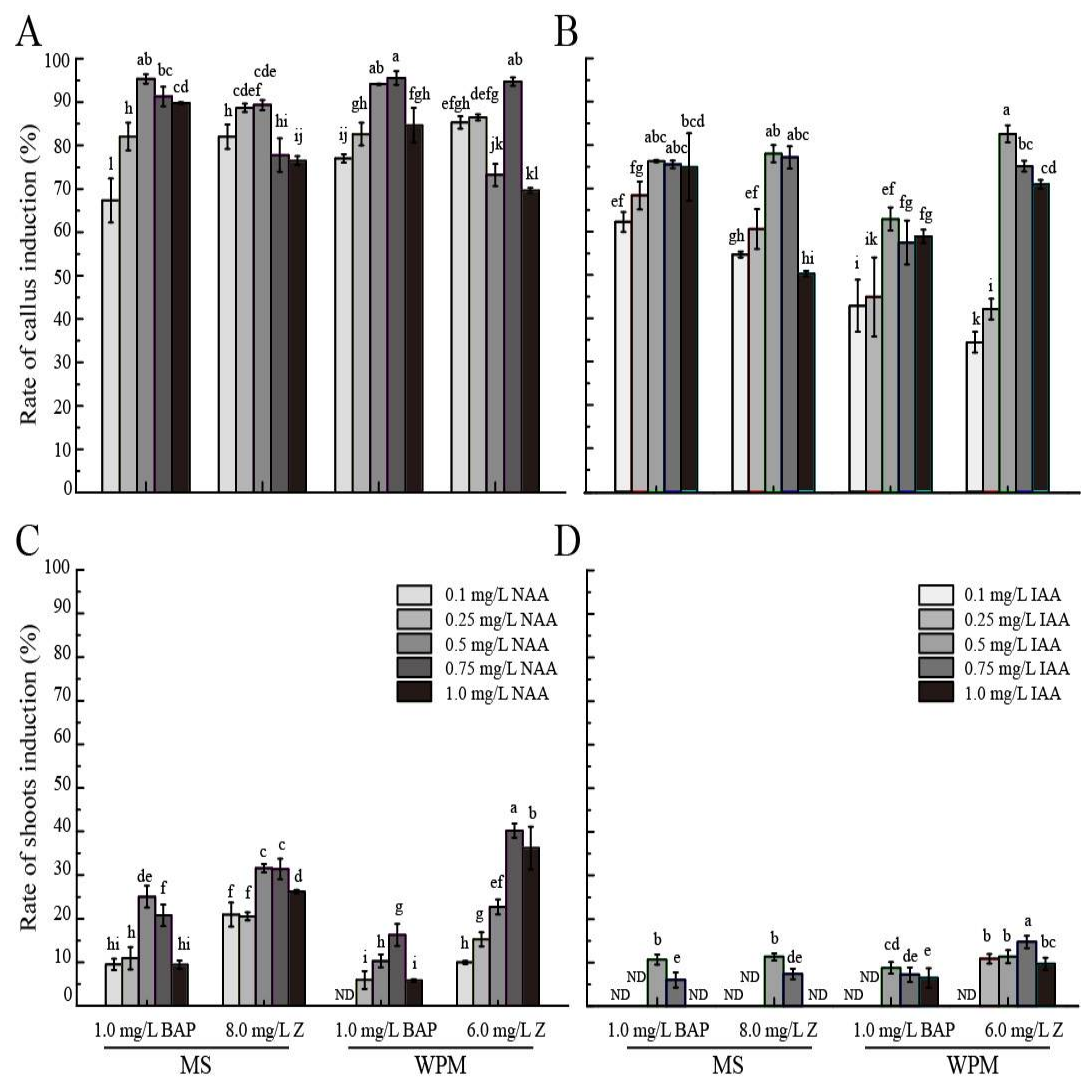

Fig. 1 Rate of callus and shoots induction from leaf explant in MS and WPM. (A) Rate of callus induction in medium with BAP/NAA and Z/NAA; (B) Rate of callus induction in medium with BAP/IAA and Z/IAA; (C) Rate of shoot induction in medium with BAP/NAA and Z/NAA; (D) Rate of shoot induction in medium with BAP/IAA and Z/IAA; Bars are the average frequencies of regeneration from 50 explants in five vessels per treatment, each experiment was repeated at least three times. In each separate graph, bars do not share the same small letter labels are significantly different at $\mathrm{p} \leq 0.05$. ND on the $\mathrm{x}$-axis means not detectable.
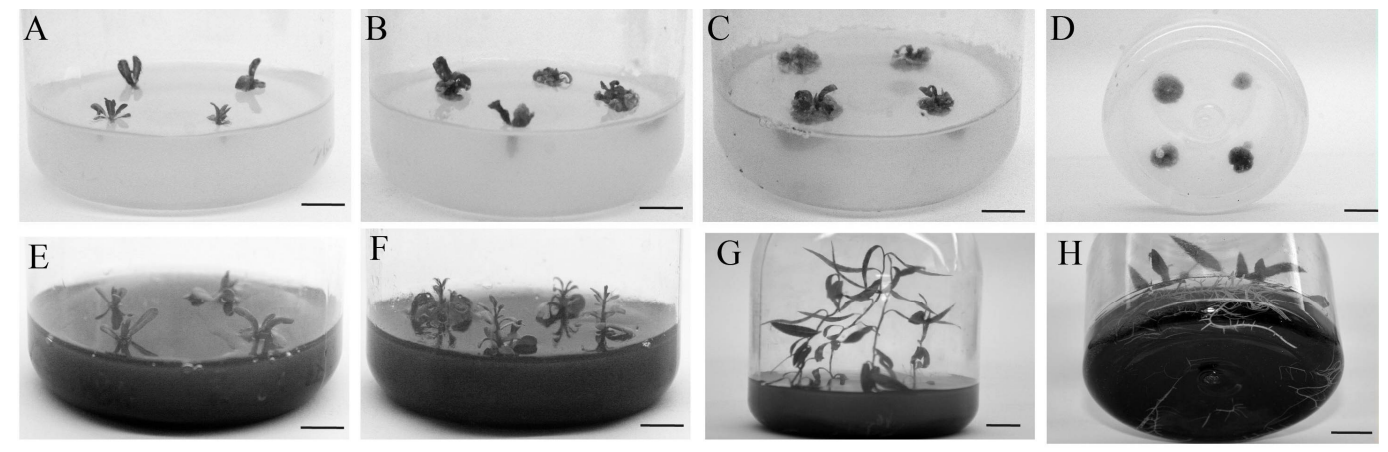

Fig. 2. Comparison of rooting medium with $(\mathrm{A}-\mathrm{D})$ or without $(\mathrm{E}-\mathrm{H})$ activated charcoal. (A) and (E) shoots were transferred to rooting medium; (B) and (F) growth status of shoots (3 weeks after transferring to rooting medium); (C) and (G) growth status of shoots (5 weeks after transferring to rooting medium); (D) and (H) callus and roots on the two different media. $\operatorname{Bar}(\mathrm{A}-\mathrm{H})=1.0 \mathrm{~cm}$. 
Leaves, stem apex, and stem with axil were used for shoots micropropagation. The same protocol was conducted according to the procedure described above, and the optimum PGRs combination and concentration on both MS and WPM media was obtained (Table 2).

Table 2. The optimal medium for callus and shoots induction on different media from leaves, stem apex and stem with axil of $S$. matsudana in vitro.

\begin{tabular}{llll}
\hline Explants & Optimal medium $(\mathrm{mg} / \mathrm{l})$ & $\begin{array}{l}\text { Rate of callus } \\
\text { induction }(\%)\end{array}$ & $\begin{array}{l}\text { Rate of shoot } \\
\text { induction }(\%)\end{array}$ \\
\hline $\begin{array}{l}\text { Leaves } \\
\text { Stem apex }\end{array}$ & WPM with $6.0 \mathrm{Z}+0.75 \mathrm{NAA}$ & $94.7 \pm 0.98$ & $40.2 \pm 1.61$ \\
$\begin{array}{l}\text { Stem with axil } \\
\text { axillary }\end{array}$ & MS with $8.0 \mathrm{Z}+1.0 \mathrm{NAA}$ & $81.2 \pm 2.44$ & $25.2 \pm 0.77$ \\
\hline
\end{tabular}

Rate of callus induction was defined as the percentage of explants with white and spongy callus in total explants. About 50 explants were cultured for each treatment and the data were calculated from at least three independent experiments. Numbers with different letters in the table indicate significant differences by the DMRT $(p \leq 0.05)$.

The benefit of activated charcoal (AC) for rooting of micropropagated shoots was reported in several plants (Chen et al. 2012, Kim and Sang 2017, Thomas 2008, Wang and Huang 1976). The addition of AC in medium not only promoted root production, but also reduced the formation of callus at the base of the shoots or explants (Yang et al. 2006). When rooted without additives, Salvia Africana-lutea plantlets produced calli at the shoot base, and this problem was solved by supplementing 0.1 g/l AC (Makunga and Van Staden 2008). The same role of AC was reported on root induction of in vitro shoots of Curcuma zedoaria (Loc et al. 2005). After the adventitious shoots reached a length more than $2 \mathrm{~cm}$, they were excised and transferred to rooting media containing the same PGRs with $1.0 \mathrm{mg} / \mathrm{l} \mathrm{AC}$. Shoots $(2-3 \mathrm{~cm}$ long) were transferred to the rooting medium (Fig. 2A). Unfortunately, the root was not visible after culturing, and bulk of callus was produced at the base of the shoot after 3 weeks (Fig. 2C, D). Activated charcoal (1.0 $\mathrm{mg} / \mathrm{l}$ ) was added in the medium, and the root appeared after 2 weeks (Fig. 2E-H).

A two-step micropropagation system involving calli and shoot induction from leaf and stem explants on MS and WPM media containing different concentrations of BAP or Z and NAA of $S$. matsudana was established. This regeneation procedure, utilizing leaf and stem have never been described before for S. matsudana, and now on would faciliate the transformation and genetic modification of Salix species.

\section{Acknowledgments}

This work was supported by The Fundamental Research Funds for the Central Non-profit Research Institution of Chinese Academy of Forestry (CAFYBB2018QB001). The authors would like to thank LetPub (www.letpub.com) for providing linguistic assistance during the preparation of this manuscript.

\section{References}

Abogadallah GM and Quick WP 2010. Fast versatile regeneration of Trifolium alexandrinum L. Plant Cell, Tiss. Org. Cult. 100: 39-48.

Agrawal DC and Gebhardt K 1994. Rapid micropropagation of hybrid willow (Salix) established by ovary culture. J. Plant Physiol. 143: 763-765.

Argus GW 1997. Intrageneric classification of Salix (Salicaceae) in the new world. Systematic Botany Monographs, pp. 1-121. 
Christensen B, Sriskandarajah S, Serek M and Müller R 2008. In vitro culture of Hibiscus rosa-sinensis L.: Influence of iron, calcium and BAP on establishment and multiplication. Plant Cell, Tiss. and Org. Cult. 93: $151-161$.

Dowling D and Doty S 2009. Improving phytoremediation through biotechnology. Current Opinion in Biotechnology 20: 204-206.

Guo B, Gao M and Liu CZ 2007. In vitro propagation of an endangered medicinal plant Saussurea involucrata Kar. et Kir. Plant Cell Reports 26: 261-265.

Karp A, Hanley S, Trybush S, Macalpine W, Pei M and Shield I 2011. Genetic improvement of willow for bioenergy and biofuels. J. Integrative Plant Biology 53: 151-165.

Krishna G, Reddy PS, Nair NA, Ramteke P and Bhattacharya P 2010. In vitro direct shoot regeneration from proximal, middle and distal segment of Coleus forskohlii leaf explants. Physiology and Molecular Biology of Plants 16: 195-200.

Loc NH, Duc DT, Kwon TH and Yang MS 2005. Micropropagation of zedoary (Curcuma zedoaria Roscoe) A valuable medicinal plant. Plant Cell, Tiss. and Org. Cult. 81: 119-122.

Lyyra S, Lima A and Merkle SA 2006. In vitro regeneration of Salix nigra from adventitious shoots. Tree Physiology 26: 969-975.

Neuner H and Beiderbeck R 1993. In vitro propagation of Salix caprea L. by single node explants. Silvae Genetica 42: 308-308.

Xu J, Wang Y, Zhang Y and Chai T 2008. Rapid in vitro multiplication and ex vitro rooting of Malus zumi (Matsumura) Rehd. Acta Physiologiae Plantarum 30: 129-132.

Yang J, Yi J, Yang C and Li C 2013. Agrobacterium tumefaciens-mediated genetic transformation of Salix matsudana Koidz. using mature seeds. Tree Physiol. 6: 628-639.

Yang L, Xu CJ, Hu GB and Chen KS 2006. Direct shoot organogenesis and plant regeneration in Fortunella crassifolia. Biologia plantarum 50: 729-732.

Zhou Y, Gao Z, Gao S, Sun F, Cheng P and Li F 2012. In vitro adventitious shoot regeneration via indirect organogenesis from inflorescence explants and peroxidase involvement in morphogenesis of Populus euphratica Olivier. Appl. Biochem. Biotechnol. 168: 2067-2078.

Chen, X.W., L. Shao, L. Liang, and Z.T. Pan. 2012. Effect of activated charcoal on rooting in tissue culture seedling of begonia fimbristipula on Dinghushan mountain. journal of chinese medicinal materials. 35:1369.

Kim, J.K., and U.P. Sang. 2017. Enhancement of in vitro rooting through growth media, gelling agents and activated charcoal in Lycium chinense. Online Journal of Biological Sciences. 17:151-156.

Thomas, T.D. 2008. The role of activated charcoal in plant tissue culture. Biotechnology Advances. 26:618-631.

Wang, P.J., and L.C. Huang. 1976. Beneficial effects of activated charcoal on plant tissue and organ cultures. Vitro. 12:260-262. 